\title{
Enhanced uptake in 2D- and 3D- lung cancer cell models of redox responsive PEGylated nanoparticles with sensitivity to reducing extra- and intracellular environments
}

\author{
Claudia Conte ${ }^{1}$, Francesca Mastrotto ${ }^{1,2}$, Vincenzo Tarescoํ․ Aleksandra Tchoryk ${ }^{1}$, \\ Fabiana Quaglia ${ }^{3}$, Snjezana Stolnik ${ }^{1}$, and Cameron Alexander ${ }^{1 *}$
}

\begin{abstract}
${ }^{1}$ Division of Molecular Therapeutics and Formulation, School of Pharmacy, University of Nottingham, UK, ${ }^{2}$ Department of Pharmaceutical and Pharmacological Sciences, University of Padova, Padova, Italy, ${ }^{3}$ Drug Delivery Laboratory, Department of Pharmacy, University of Napoli Federico II, Napoli, Italy. F. Mastrotto and V. Taresco contributed equally to this work.
\end{abstract}

*Corresponding author:

Prof. Cameron Alexander:

tel $+44(0) 1158467678$

cameron.alexander@nottingham.ac.uk 


\section{Abstract}

In the treatment of lung cancer, there is an urgent need of innovative medicines to optimize pharmacological responses of conventional chemotherapeutics while attenuating side effects. Here, we have exploited some relatively unexplored subtle differences in reduction potential, associated with cancer cell microenvironments in addition to the wellknown changes in intracellular redox environment. We report the synthesis and application of novel redox-responsive PLGA (poly(lactic-co-glycolic acid)) -PEG (polyethylene glycol) nanoparticles (RR-NPs) programmed to change surface properties when entering tumor microenvironments, thus enhance cell internalization of the particles and their drug cargo. The new co-polymers, in which PEG and PLGA were linked by 'anchiomeric effector' dithiylethanoate esters were synthesized by a combination of ring-opening polymerization and Michael addition reactions and employed to prepare NPs. Non redox-responsive nanoparticles (nRR-NPs) based on related PLGA-PEG copolymers were also prepared as comparators. Spherical NPs of around $120 \mathrm{~nm}$ diameter with a low polydispersity index and negative zeta potentials as well as good drug loading of docetaxel were obtained. The NPs showed prolonged stability in relevant simulated biological fluids and a high ability to penetrate an artificial mucus layer due to the presence of the external PEG coating. Stability, FRET and drug release studies in conditions simulating intracellular reductive environments demonstrated a fast disassembly of the external shell of the NPs, thus triggering on-demand drug release.

FACS measurements and confocal microscopy showed increased and faster uptake of RRNPs in both 2D- and 3D- cell culture models of lung cancer compared to nRR-NPs. In particular, the 'designed-in' reductive instability of RR-NPs in conditioned cell media, the fast PEG release in the extracellular compartment, as well as a diminution of uptake rate in control experiments where extracellular thiols were neutralized, suggested a partial extracellular release of the PEG fringe that promoted rapid internalization of the residual NPs into cells.

Taken together, these results provide further evidence of the effectiveness of PEGylated reducible nanocarriers to permeate mucus layer barriers, and establish a new means to enhance cancer cell uptake of drug carriers by extra-and intra-cellular cleavage of proteinand cell-shielding hydrophilic blocks. 


\section{Introduction}

The need for selective therapies and personalized nanomedicines for cancer has prompted research into novel formulations which can utilise minimally invasive administration routes, and also exploit specific characteristics of the tumor type and its localization in the body. Local delivery of anti-cancer drugs to the lungs via inhalable formulations could represent a promising strategy to enhance pharmacological targeting and efficacy, while maintaining low drug levels at non-target sites and reducing side effects related to systemic administration.[1, 2] Better formulations for lung cancer are particularly needed because this disease remains one of the leading causes of cancer mortality worldwide.

Despite poly-chemotherapy, close to $70 \%$ of patients with lung cancer present locally advanced or metastatic disease at the time of diagnosis. In such cases, the prognosis is poor and patients with advanced disease commonly die within one year. For this reason, many different lung delivery technologies have been explored in order to optimize pharmacological response while attenuating side effects of conventional therapies. Nevertheless, the biggest obstacles in lung cancer diseases are related to the physiological and pathological barriers of the lung, as well as the tumor microenvironment which is highly variable among individuals and cancer types/stages. In particular, the success of inhalation therapies for severe and chronic lung diseases, including cancer, strongly depends upon: i) site and extent of drug deposition in the respiratory tract; ii) drug permeation through airway mucus; iii) macrophage clearance escape and iv) interaction with target cells.[3] As a consequence, drug delivery carriers which can reach the deep lung and selectively target cancer cells are needed. $[4,5]$

Delivery systems based on PEGylated nanoparticles (NPs) have been shown to penetrate rapidly across mucus layers, avoiding clearance mechanisms and thereby providing targeting to underlining epithelial tissues.[6] However, the properties of the PEG chains, including chain length as well as the molecular weight, can affect the conformation and the density of the hydrophilic corona on NP surfaces, thus modifying the penetration across mucus barriers.[7] In addition, even when accumulated within the deep lung, it is still necessary to discriminate between normal cells and the tumor sites, and thus not only is mucus-penetration required but also a selective delivery mechanism in situ is needed. Accordingly, the development of inhalable NPs which can respond in the tumor microenvironment to target specific cells, or to release a therapeutic at a particular site, is of significant interest.

A number of "smart" polymeric NPs have been developed that release drugs in response to internal or external stimuli, such as $\mathrm{pH}$, redox potential, up-regulated proteins, temperature, magnetic and light, and some have demonstrated improved tumor targeting abilities and antitumor effects.[8-10] A particular focus has been to exploit the differences in reduction potential between normal tissues and certain cancer cells, since it has been established that some tumor intracellular compartments are characterized by reductive glutathione (GSH) tripeptides at concentrations (about 2-10 mM), which are $100-1000$ times higher than those in extracellular fluids and normal tissues (about 2-20 $\mu \mathrm{M})[11]$. For this 
reason, GSH-responsive NPs have been recognized as promising intracellular drug delivery systems for cancer therapy.[12-15]

Several recent reviews have discussed redox responsive gene delivery polyplexes, liposomes, micelles, nanoparticles, gels and antibody-drug conjugates[12, 16, 17]. One example is Mylotarg ${ }^{\circledR}$, which was the first FDA approved drug delivery system containing a linker system with a disulfide bond[18], although this product was subsequently withdrawn from the market. Although the introduction of disulfide linkages has been shown to enhance drug release via well-established intracellular mechanisms, in recent years, some further evidence has been obtained that certain reactive and reductive processes can also take place in extracellular regions and at cancer cell surfaces due to the presence of extracellular thiols and cell surface-associated redox enzymes.[19-21]. For example, Kwok and coworkers synthesized nonreducible and reducible poly(ethylene glycol) (PEG)-peptides, and reported a higher cellular uptake for the reducible PEG-peptide DNA condensate, indicating that extracellular mechanisms might be involved.[22] In support of their findings, Feener et al. [19] synthesized a radioiodinated tyramine linked through a disulfide bond to an nondegradable carrier, poly(D-lysine), known to be efficiently endocytosed. This compound was tested in cultured Chinese hamster ovary cells and the disulfide cleavage was measured via the release of acid-soluble radioactive products over time. When sulfhydryl groups present at the cell surface were blocked with a cell-impermeant sulfhydryl reagent, the initial phase of disulfide cleavage was inhibited, indicating that disulfide bond reduction of the reducible peptides was initiated at the cell surface. [20] A later study found that reducible polylysine based DNA nanoparticles enhanced cellular uptake and in vitro gene transfer via an extracellular mechanism, demonstrated by blocking extracellular free thiols. As controls, a series of DNA NPs prepared with stabilized disulfide bonds survived the extracellular environment without aggregation but lost the superior gene transfer ability[19]. Despite these findings, so far no clinically relevant data on in vivo cancer models are available, so a deeper investigation of extracellular redox responsiveness is needed. However, it can be envisaged that drug delivery systems might be designed which could respond to changes in the surface biochemistry and redox potential at cancer cell surfaces, in addition to an intracellular response.

With this in mind, we describe here a novel double extra- and intracellular redoxresponsive polymer intended for inhaled therapy of lung cancer. The key design criteria were; 1 ) a short hydrophilic polymer block to form a mucus-penetrating external layer; 2) a disulfide bond specifically placed such that it not only links the external hydrophilic shell to a hydrophobic drug-carrying core, but is accessible to extracellular thiols and reducing agents at cancer cell surfaces; 3 ) linker chemistry which generates new nucleophilic species on disulfide cleavage and 4) backbone chemistry of the hydrophobic core which allows for accelerated degradability upon nucleophile generation. We based our materials design on amphiphilic bioreducible polyethylene glycol (PEG)-poly(lactic-co-glycolic acid) (PLGA) block copolymers, as these systems are well-known for biodegradability, drug loading properties as well as suitability in pulmonary delivery of different drugs[23] and application in the clinic.[24] We therefore designed a linear diblock copolymer in which dithiylethanoate esters were used to link the PLGA and the PEG blocks such that reductive cleavage of the disulfide was predisposed to generate nucleophilic end groups which simultaneously 
liberated the PEG shell from the NPs and started the degradation of the PLGA core. The colloidal properties of the NPs, their drug loading abilities and their redox responsiveness in a simulated intracellular reductive environment were investigated. As the particles were intended for pulmonary administration, the impact of the release of the PEG shell on NP transport through a simulated mucus layer was assessed in vitro. Finally, by using Förster Resonance Energy Transfer (FRET) methods, we characterized the cell internalization performance of NPs in different 2D and 3D- cell culture models of lung cancer. 


\section{Methods}

Materials. All solvents and reagents were of analytical or HPLC grade and purchased from Sigma or Fisher Scientific unless otherwise stated. Deuterated solvents, and monomers glycolide and DL-lactide were from Sigma. The monomers were recrystallized from ethyl acetate prior to use. Poly(ethylene glycol) methyl ether (mPEG) and $\alpha$-methoxy- $\omega$-amino poly (ethylene glycol) (mPEG-NH$)$ with $\mathrm{Mn}_{2}=2.0 \mathrm{kDa}$ were purchased from Iris Biotech $\mathrm{GmbH}$ (Germany) and dried by azeotropic distillation from toluene prior to use. Docetaxel (DTX, MW= 807.88) was purchased from LC laboratories (USA). 1,1'-dioctadecyl-3,3,3',3'tetramethylindocarbocyanine perchlorate (DiL) and 3,3'-dioctadecyloxacarbocyanine perchlorate (DiO) were purchased from Life Technologies (UK). Dialysis membrane (MWCO 3500 , regenerated cellulose) was used as received from Spectrapor. Tin (II)-2ethylhexanoate $\left(\mathrm{Sn}(\mathrm{Oct})_{2}\right)$, acryloyl chloride, triethylamine (TEA), dithioethanol, poly(vinyl alcohol) (PVA, Mowiol ${ }^{840-88, M w ~ 31000), ~ 5,5 '-D i t h i o b i s(2-n i t r o b e n z o i c ~ a c i d) ~(D T N B), ~}$ sodium chloride, potassium phosphate dibasic and potassium phosphate monobasic, sodium azide, L-glutathione reduced (GSH), dithiothreitol (DTT), magnesium chloride, sterile egg yolk emulsion, mucin, DTPA, potassium chloride, sodium phosphate dibasic, sodium sulfate, calcium chloride dehydrated, sodium acetate, sodium bicarbonate, sodium citrate dehydrate, Rhodamine 6G (Rhod6G), Fluorescein Sodium salt Fluo, iodine and barium chloride were used as received from Sigma Aldrich.

\section{Synthesis of block copolymers.}

Synthesis of PLGA-PEG block copolymer.

PLGA-PEG block copolymers were synthesized by ring-opening polymerization (ROP) as previously reported using $\mathrm{MPEG}$ and $\mathrm{Sn}(\mathrm{Oct})_{2}$ as initiator and catalyst, respectively[25]. DL-lactide $(2.5 \mathrm{~g}, 17.5 \mathrm{mmol})$, glycolide $(2.0 \mathrm{~g}, 17.5 \mathrm{mmol})$ and $\mathrm{mPEG}_{2 \mathrm{k}}(1.4 \mathrm{~g}, 0.695 \mathrm{mmol})$ were added in a bottleneck flask and heated to $130^{\circ} \mathrm{C}$ to allow complete melting under a nitrogen atmosphere for $1 \mathrm{~h}$. $\mathrm{Sn}(\mathrm{Oct}) 2(0.5 \% \mathrm{w} / \mathrm{w}, 29.5 \mathrm{mg}, 0.007 \mathrm{mmol})$ was then added, and the mixture was stirred at $140{ }^{\circ} \mathrm{C}$ for $24 \mathrm{~h}$. The reaction mixture was cooled down to room temperature and the synthesized polymer was recovered by dissolution in DCM and precipitated in ice-cold diethyl ether three times to remove the excess of unreacted monomers and the catalyst. Finally, the precipitate was filtered and dried under reduced pressure to give a white solid product in $86 \%$ yield.

ATR-IR: $v\left(\mathrm{~cm}^{-1}\right)$ 3510, 2989, 2952, 2883, 1746, 1407, 1162, 1090.

${ }^{1} \mathrm{H}$ NMR $\left(400 \mathrm{MHz}, \mathrm{CDCl}_{3}, \mathrm{ppm}\right): \delta_{\mathrm{H}} 1.52-1.58\left(\mathrm{~m}, 150,-\mathrm{CHCH}_{3}\right), 3.36\left(\mathrm{~s}, 3,-\mathrm{OCH}_{3}\right)$, 3.62-3.64 (m, 176, - $\left.\mathrm{OCH}_{2} \mathrm{CH}_{2} \mathrm{O}-\right), 4.78-4.88$ (m, 104, - $\left.\mathrm{COCH}_{2}-\right), 5.13-5.23$ (m, $50-$ $\mathrm{COCHCH})_{3}$.

${ }^{13} \mathrm{C} \mathrm{NMR}\left(400 \mathrm{MHz}, \mathrm{CDCl}_{3}, \mathrm{ppm}\right): \delta \mathrm{c} 16.5$ (s, $\left.1,-\mathrm{CHCH}_{3}\right), 60.8\left(\mathrm{~s}, 1,-\mathrm{OCH}_{2} \mathrm{OH}\right), 69.0$ (s, 2, $\left.-\mathrm{OCH}_{2} \mathrm{CH}_{2} \mathrm{O}-\right), 70.5$ (s, 1, $-\mathrm{CHCH}_{3}$ ), 166.3 (s,1, - $\mathrm{OCOCH}$ ) 169.3 (s, 1, $-\mathrm{OCOCH} \mathrm{CH}_{2} \mathrm{OH}$.

Synthesis of PLGA-ss-PEG block copolymer.

(1) Synthesis of 2-((hydroxymethyl) disulfanyl) ethyl acrylate. The ROP initiator was prepared via a reported method with minor modifications[26]. Briefly, dithiodiethanol (10 g, 
$0.065 \mathrm{~mol}$ ) was added to a round-bottom flask equipped with three-way stopcocks connected to either a nitrogen line or a vacuum pump, and dried via azeotropic distillation with anhydrous toluene $(3 \times 20 \mathrm{~mL})$ under reduced pressure. After complete evaporation of toluene, anhydrous THF $(20 \mathrm{~mL})$ was added via a syringe under inert atmosphere. TEA (6.5 $\mathrm{g}, 0.065 \mathrm{~mol}$ ) was added to the solution which was maintained at $4{ }^{\circ} \mathrm{C}$ during drop wise addition of acryloyl chloride $(3.5 \mathrm{~g}, 0.039 \mathrm{~mol})$. The solution was allowed to warm to room temperature under magnetic stirring and left to react overnight. The solution was finally filtered to remove the chloride salt of TEA and the crude product was recovered by evaporation of THF. The product was purified by passing through silica column chromatography using petroleum ether/ ethyl acetate $70: 30$ as eluents (yield 65\%).

ATR-IR: $v\left(\mathrm{~cm}^{-1}\right) 3417,2934,2875,1717,1638,1615,1450,1407,1302,1262,1180$, 1049, 980.

${ }^{1} \mathrm{H}$ NMR (400 MHz, d6-DMSO, ppm): $\delta$ н 2.85-2.88 (t, 2, J= $12 \mathrm{~Hz},-\mathrm{SCH}_{2} \mathrm{CH}_{2} \mathrm{OH}$ ), 2.932.96 (t, 2, J=12 Hz, - $\mathrm{COOCH}_{2} \mathrm{CH}_{2} \mathrm{~S}-$ ), 3.84-3.87 (t, 2, J= $12 \mathrm{~Hz}, \quad-\mathrm{CH}_{2} \mathrm{OH}$ ), 4.39-4.42 (t, 2, $\left.J=12 \mathrm{~Hz},-\mathrm{COOCH}_{2} \mathrm{CH}_{2} \mathrm{~S}-\right), 5.84-5.87$ (dd, $\left.1, J=8 \mathrm{~Hz}, J=0.08 \mathrm{~Hz},-\mathrm{CHCHH}\right), 6.08-6.14(\mathrm{~m}$, 1, - $\mathrm{CHCHH),} \mathrm{6.39-6.44} \mathrm{(dd,} 1, \mathrm{~J}=8 \mathrm{~Hz}, \mathrm{~J}=0.08 \mathrm{~Hz},-\mathrm{CHCHH}$ ).

${ }^{13} \mathrm{C}$ NMR (400 MHz, d6-DMSO, ppm): $\delta_{\mathrm{c}} 36.7$ (s, 1, - $\mathrm{SCH}_{2} \mathrm{CH}_{2} \mathrm{O}-$ ), 41.2 (s, 1, $\mathrm{SCH}_{2} \mathrm{CH}_{2} \mathrm{OH}$ ), 60.2 (s, 1, $-\mathrm{CH}_{2} \mathrm{OH}$ ), 62.3 (s, 1, $\left.-\mathrm{SCH}_{2} \mathrm{CH}_{2} \mathrm{O}-\right)$, 127.8 (s, $1,-\mathrm{CHCH}_{2}$ ), 131.4 (s, $\left.1,-\mathrm{CHCH}_{2}\right), 166.1$ (s, $\left.1,-\mathrm{OCOCH}-\right)$.

(2) Synthesis of PLGA-S-S-ethyl acrylate. PLGA-S-S-ethyl acrylate (PLGA-SS) was synthesized by ROP using 2-((hydroxymethyl) disulfanyl) ethyl acrylate as initiator. DLlactide $(2.5 \mathrm{~g}, 0.0175 \mathrm{~mol})$, glycolide $(2.0 \mathrm{~g}, 0.0175 \mathrm{~mol})$ and 2-((hydroxymethyl) disulfanyl) ethyl acrylate $(0.144 \mathrm{~g}, 0.695 \mathrm{mmol})$ were added in a bottleneck flask and heated to $130{ }^{\circ} \mathrm{C}$ for complete melting under nitrogen atmosphere for $1 \mathrm{~h} .0 .5 \% \mathrm{w} / \mathrm{w} \mathrm{Sn}(\mathrm{Oct}) 2(29.5 \mathrm{mg}, 0.007$ $\mathrm{mmol}$ ) was then added, and the mixture was stirred at $140{ }^{\circ} \mathrm{C}$ for $24 \mathrm{~h}$. The synthesized polymer was recovered by dissolution in DCM and precipitated in ice-cold diethyl ether three times to remove the unreacted monomers. Finally, the precipitate was filtered and dried under reduced pressure to give a white solid product in $95 \%$ yield.

ATR-IR: $v\left(\mathrm{~cm}^{-1}\right)$ 3513, 2996, 2960, 2882, 1740, 1424, 1384, 1158, 1118, 1082, 668.

${ }^{1} \mathrm{H}$ NMR $\left(400 \mathrm{MHz}, \mathrm{CDCl}_{3}, \mathrm{ppm}\right): \delta_{\mathrm{H}} 1.57-1.61\left(\mathrm{~m}, 150,-\mathrm{CHCH}_{3}\right), 2.94-3.00(\mathrm{~m}, 4$, $\mathrm{CH}_{2} \mathrm{SCH}_{2}$ ), 4.27-4.32 (m, 2, - $\left.\mathrm{COOCH}_{2} \mathrm{CH}_{2} \mathrm{~S}-\right)$, 4.43-4.48 (m, 2, - $\left.\mathrm{SCH}_{2} \mathrm{CH}_{2} \mathrm{OCOCH}-\right)$, 4.70$4.93\left(\mathrm{~m}, 104,-\mathrm{CH}_{2} \mathrm{OH}\right), 5.20-5.26\left(\mathrm{~m}, 50-\mathrm{COCHCH}_{3}\right), 5.88-5.91$ (d, $1, \mathrm{~J}=8 \mathrm{~Hz}, \mathrm{~J}=0.08 \mathrm{~Hz}$, $-\mathrm{CHCH} H), 6.12-6.19(\mathrm{~m}, 1,-\mathrm{CHCHH}), 6.44-6.48(\mathrm{dd}, 1, \mathrm{~J}=8 \mathrm{~Hz}, \mathrm{~J}=0.08 \mathrm{~Hz},-\mathrm{CHCHH})$.

${ }^{13} \mathrm{C} \mathrm{NMR}\left(400 \mathrm{MHz}, \mathrm{CDCl}_{3}, \mathrm{ppm}\right): \delta \mathrm{c} 16.5\left(\mathrm{~s}, 1,-\mathrm{CHCH}_{3}\right), 60.8\left(\mathrm{~s}, 1,-\mathrm{CH}_{2} \mathrm{OH}\right), 65.7$ (s, 2, $\mathrm{CH}_{2} \mathrm{CH}_{2} \mathrm{SSCH}_{2} \mathrm{CH}_{2}$ ), 69.1 (s, $\left.1,-\mathrm{CHCH}_{3}\right), 166.2$ (s,1, - OCOCH-), $169.3\left(\mathrm{~s}, 1,-\mathrm{OCOCH}_{2}\right.$ ).

(3) Synthesis of PLGA-S-S-PEG. The block copolymer PLGA-S-S-PEG was synthesized by Aza-Michael Addition between the amino group of $\mathrm{mPEG}-\mathrm{NH}_{2}$ and the acrylic end group of PLGA-SS. mPEG-NH2 $(2 \mathrm{~g}, 0.001 \mathrm{~mol})$, PLGA-SS $(2.5 \mathrm{~g}, 0.5 \mathrm{mmol})$ and TEA $(0.1 \mathrm{~g}$, $0.001 \mathrm{~mol}$ ) were added to a round-bottom flask equipped with three-way stopcocks connected to either a nitrogen line or a vacuum pump, and dried via azeotropic distillation with anhydrous toluene $(3 \times 20 \mathrm{~mL})$ under reduced pressure. After complete evaporation of toluene, anhydrous THF $(10 \mathrm{~mL})$ was added via a syringe under inert atmosphere. TEA $(0.1$ 
$\mathrm{g}, 0.001 \mathrm{~mol}$ ) was added to the solution which was maintained under magnetic stirring at 65 ${ }^{\circ} \mathrm{C}$ for 6 days. The synthesized polymer was filtered, precipitated in ice-cold diethyl ether (twice) and ice-cold methanol (twice) to remove the unreacted reagents, and finally dried under reduced pressure to yield a white solid product (yield $70 \%$ ).

ATR-IR: $v\left(\mathrm{~cm}^{-1}\right)$ 3509, 2997, 2957, 2881, 1740, 1417, 1161, 1125, 1075, 668.

${ }^{1} \mathrm{H}$ NMR (400 MHz, $\left.\mathrm{CDCl}_{3}, \mathrm{ppm}\right): \delta_{\mathrm{H}} 1.57-1.61\left(\mathrm{~m}, 150,-\mathrm{CHCH}_{3}\right), 3.13-3.19(\mathrm{~m}, 4$, $\left.\mathrm{CH}_{2} \mathrm{SSCH}_{2-}\right) 3.40$ (s, 3, - $\left.\mathrm{OCH}_{3}\right), 3.66-3.68$ (m, 176, - $\left.\mathrm{OCH}_{2} \mathrm{CH}_{2} \mathrm{O}-\right)$, 4.28-4.33 (m, 2, $\left.\mathrm{SCH}_{2} \mathrm{CH}_{2} \mathrm{OCOCH}-\right)$, 4.79-4.93 (m, 104, - $\left.\mathrm{COCH}_{2}-\right)$, 5.17-5.27 (m, $\left.50-\mathrm{COCHCH}_{3}\right)$.

${ }^{13} \mathrm{C} \mathrm{NMR}\left(400 \mathrm{MHz}, \mathrm{CDCl}_{3}, \mathrm{ppm}\right): \delta_{\mathrm{c}} 16.5$ (s, 1, $\left.-\mathrm{CHCH}_{3}\right), 40.3$ (s, 2, $\left.-\mathrm{CH}_{2} \mathrm{SSCH}_{2}-\right), 60.8$ (s, 1, $-\mathrm{OCH}_{3}$ ), 69.0 (s, 2, $-\mathrm{OCH}_{2} \mathrm{CH}_{2}$ ), 70.5 (s, 1, $-\mathrm{CHCH}$ ), 166.3 (s, 1, - $\left.\mathrm{OCOCH}-\right), 169.3$ $\left(\mathrm{s}, 1,-\mathrm{OCOCH}_{2}\right)$.

\section{Characterization of polymers}

Spectroscopy: ${ }^{1} \mathrm{H}$ - and ${ }^{13} \mathrm{C}$ NMR spectra were recorded at $25^{\circ} \mathrm{C}$ on a Bruker Avance III $400 \mathrm{MHz}$ spectrometer. All chemical shifts are reported in ppm ( $\delta)$ relative to tetramethylsilane or referenced to the chemical shifts of residual solvent resonances. Multiplicities are described with the following abbreviations: $\mathrm{s}=$ singlet, $\mathrm{br}=$ broad, $\mathrm{d}=$ doublet, $\mathrm{t}=$ triplet, $\mathrm{m}=$ multiplet, $\mathrm{dd}=$ doublet of doublets. Chemical shifts were assigned in parts per million (ppm). MestReNova 6.0.2 copyright 2009 (Mestrelab Research S. L.) was used for analysing the spectra.

FT-IR spectra were recorded with an Attenuated Total Reflection spectrophotometer (Agilent Technologies Cary 630 FTIR) equipped with a diamond single reflection ATR unit. Mass spectrometry was carried out using a Micromass LCT ToF with electrospray ionization and OpenLynx software. IR analysis were performed by using SpectraGryph version1.0.

Chromatography: Size exclusion chromatography (SEC) measurements of PLGA-based copolymers were performed at $25{ }^{\circ} \mathrm{C}$ by using a PL50 Polymer Laboratories system equipped with a refractive index detector, employing 2 mixed bed PLgel Mixed-D columns $\left(5 \mu \mathrm{m}\right.$ bead, $7.8 \times 300 \mathrm{~mm}$ ) columns with a matching guard $(7.8 \times 50 \mathrm{~mm})$, using $\mathrm{CHCl}_{3}$ as the mobile phase at a flow rate of $1 \mathrm{~mL} / \mathrm{min}$, and polystyrene standards as reference $(526000-820 \mathrm{~g} / \mathrm{mol})$ in $\mathrm{CHCl}_{3}$. Sample concentration of $5 \mathrm{mg} / \mathrm{mL}$ were employed. Molecular weights and dispersity values were calculated using Cirrus GPC 3.0 software.

Thermal analysis: Thermal properties of the materials were studied by differential scanning calorimetry (DSC) (Q2000, TA Instruments, Leatherhead, UK) at a heating rate of $10^{\circ} \mathrm{C} / \mathrm{min}$. The data were analysed using Thermal Analysis Software (Version 4.5.05A). Hermetic crimped pans were utilized for the analysis of the samples, using empty pans as the reference and the DSC cell was purged with $\mathrm{N}_{2(\mathrm{~g})}$ at a flow rate of $50 \mathrm{ml} / \mathrm{min}$. Thermal transitions were analysed in the temperature range between -40 to $120^{\circ} \mathrm{C}$.

\section{Nanoparticles preparation and characterization}

Preparation of Nanoparticles. NPs were prepared by the double emulsion-solvent evaporation method. In a typical procedure, $0.1 \mathrm{~mL}$ of an internal water phase was added to a DCM solution $(1 \mathrm{~mL}$ ) of the copolymer $(10 \mathrm{mg})$, and sonicated for $1 \mathrm{~min}$ at $3 \mathrm{~W}$ (Sonicator 3000 , Misonix, USA) by a microtip probe. This first emulsion was poured in water $(10 \mathrm{~mL})$ in the presence of PVA $0.5 \% \mathrm{~W} / \mathrm{v}$, and sonicated again for $5 \mathrm{~min}$ at $3 \mathrm{~W}$. Thereafter, the organic 
solvent was evaporated by mechanical stirring for $4 \mathrm{~h}$ at r.t. and then filtered $(0.45 \mu \mathrm{m})$. NPs were collected by centrifugation $\left(17000 \mathrm{xg}, 30 \mathrm{~min}, 4^{\circ} \mathrm{C}\right)$ after washing twice with distillated water to remove PVA. NPs were then redispersed in water $(1 \mathrm{~mL})$, freeze-dried for $24 \mathrm{~h}$ and kept at $4^{\circ} \mathrm{C}$. Recovery yield of production process was evaluated by weighing the solid residue after freeze-drying. Results are expressed as the ratio of the actual NPs weight to the theoretical polymer weight $x 100$.

Size, zeta potential and morphological studies. The hydrodynamic diameter $\left(D_{H}\right)$, polydispersity index $(\mathrm{PI})$ and zeta potential of NPs were determined on a Zetasizer Nano ZS (Malvern Instruments Ltd.). A NP dispersion was diluted in Milli-Q water at intensity in the range $10^{4}-10^{6} \mathrm{counts} / \mathrm{s}$ and measurements were performed at $25^{\circ} \mathrm{C}$ on $90^{\circ}$ angle. Results are reported as the mean of three separate measurements of three different batches $(n=9)$ \pm standard deviation (SD). The morphology of the NPs was examined by transmission electron microscopy (TEM). Samples were imaged using a JEOL (JEM-10-10) electron microscope. A few drops were added onto a copper grid and allowed to dry in air. NPs were negatively stained with $2 \%$ phosphotungstic acid solution.

Colloidal stability of NPs. Fixed aqueous layer thickness (FALT) was measured by monitoring the influence of ionic strength on particle zeta potential. Different amounts of $\mathrm{NaCl}$ stock solutions at different concentrations were added to a NP dispersion in water (0.5 $\mathrm{mg} / \mathrm{mL}$ ) and $\zeta$ potentials of the samples were measured. A plot of $\ln (\zeta)$ against $\kappa(\kappa=3.33$ $\mathrm{C}^{0.5} \mathrm{NaCl}$ ) gives a straight line where the slope represents the thickness of the PEG shell in $\mathrm{nm}\left(\mathrm{d}_{\text {shell }}\right)[27,28]$. To determine the stability of NPs under physiologically relevant conditions, a known amount of NPs was dispersed in $10 \mathrm{mM}$ phosphate buffer saline at $\mathrm{pH}$ 7.4 containing sodium chloride $(137 \mathrm{mM})$ and potassium chloride $(2.7 \mathrm{mM})(\mathrm{PBS}), \mathrm{NaCl}$ $0.9 \% \mathrm{w} / \mathrm{v}$ or Simulated Interstitial Lung Fluid (SILF) and incubated at $37^{\circ} \mathrm{C}$ for different times. SILF was prepared following the preparation instructions dictated by Marques et al. [29]. Briefly, $1 \mathrm{~L}$ of SILF contains $0.095 \mathrm{~g}$ of $\mathrm{MgCl}_{2}, 6.019 \mathrm{~g}$ of NaCl, $0.298 \mathrm{~g}$ of KCl, 0.126 $\mathrm{g}$ of sodium phosphate dibasic, $0.063 \mathrm{~g}$ of sodium sulfate, $0.368 \mathrm{~g}$ of calcium chloride dehydrated, $0.574 \mathrm{~g}$ of sodium acetate, $2.604 \mathrm{~g}$ of sodium bicarbonate and $0.097 \mathrm{~g}$ of sodium citrate dehydrate. Size measurements of the samples were taken after $1 \mathrm{~h}, 24 \mathrm{~h}$, $48 \mathrm{~h}$ and $72 \mathrm{~h}$ of incubation. The stability of NPs was demonstrated by the absence of macroscopic aggregates and unchanged initial particle size.

Encapsulation studies. NPs were loaded with both hydrophilic and hydrophobic drug models, alone and in combination. In particular, Rhod6G and FITC were selected as hydrophilic compounds whereas DiL and DiO were chosen as lipophilic tracers. Loaded NPs were prepared by the double emulsion-solvent evaporation method as described above. Before the emulsion processes, Rhod6G $(0.1 \mathrm{mg}) \mathrm{md}$ Fluo $(0.02 \mathrm{mg})$ were dissolved in the internal water phase, alone or in association, thus forming Rhod6G-NPs, Fluo-NPs and Rhod6G/Fluo-NPs. DiL $(0.1 \mathrm{mg})$ and DiO $(0.1 \mathrm{mg})$ were dissolved in the DCM solution containing the polymer, alone or in association, thus giving DiL-NPs, DiO-NPs and DiL/DiONPs.

Rhod6G and Fluo loading inside NPs was assessed by dissolving $1 \mathrm{mg}$ of freeze dried NPs in $500 \mu \mathrm{L}$ of DCM under stirring for $1 \mathrm{~h}$. Thereafter, $500 \mu \mathrm{L}$ of water were added and the sample stirred for $1 \mathrm{~h}$ further. After centrifugation at $5000 \mathrm{rpm}$ for $10 \mathrm{~min}$, the supernatant was collected and analysed for Rhod6G and Fluo quantification by UV spectrophotometry 
(Varian Cary Eclipse, UK) at 528 and $490 \mathrm{~nm}$, respectively. The concentration of Rhod6G and/or Fluo was calculated by means of a standard calibration curve derived for water solutions of the specific drug at known concentrations $(0.4-20 \mu \mathrm{g} / \mathrm{mL})$. Potential interference of Rhod6G on Fluo absorbance was preliminary assessed spiking a Fluo solution in water with different amount of Rhod6G. Potential interference of Fluo on Rhod6G absorbance was preliminary assessed spiking a Rhod6G solution in water with different amount of Fluo. DiL and DiO loading inside NPs was assessed by dissolving $1 \mathrm{mg}$ of freeze dried NPs in $1 \mathrm{~mL}$ of DCM under stirring for $1 \mathrm{~h}$. Samples were analysed for DiL and DiO quantification by UV spectrophotometry at 543 and $488 \mathrm{~nm}$, respectively. The concentration of DiL and/or DiO was calculated by means of a standard calibration curve derived for DCM solutions of the specific drug at known concentrations $(0.5-60 \mu \mathrm{g} / \mathrm{mL})$. Potential interferences of DiL on DiO absorbance and vice versa were assessed by spiking a DiO solution in DCM with different amounts of DiL, or a DiL solution in DCM with different amount of DiO. To verify a possible interference of copolymers on DiL/DiO quantitative analysis, an amount of unloaded NPs was dissolved in DCM and analysed under the same conditions reported for the drugs.

\section{Redox responsiveness of nanoparticles}

NP stability. To determine the stability of NPs under reductive conditions, a known amount of NPs was dispersed in PBS $10 \mathrm{mM} \mathrm{pH} 7.4$ enriched with $\mathrm{GSH}(5,10$ and $20 \mathrm{mM})$ or DTT $(10 \mathrm{mM})\left(\mathrm{NP}\right.$ concentration was $1.5 \mathrm{mg} / \mathrm{mL}$ ) and incubated at $37^{\circ} \mathrm{C}$ for different times. Size measurements of the samples were taken by dynamic light scattering on a Zetasizer and a Viscotek 802 instrument after 30 min and $24 \mathrm{~h}$ of incubation.

Release studies. In vitro release of Rhod6G from NPs in PBS with or without GSH 10 $\mathrm{mM}$ was investigated by a dialysis method. A known amount of NPs $(2 \mathrm{mg})$ was dispersed in $0.5 \mathrm{~mL}$ of PBS solution and placed in a dialysis bag $\left(\mathrm{MWCO}=3500 \mathrm{Da}\right.$, Spectra/Por $\left.{ }^{\circledR}\right)$. The sample was placed in $8 \mathrm{~mL}$ of PBS (sink condition) and kept at $37^{\circ} \mathrm{C}$. At selected time intervals, $1 \mathrm{~mL}$ of release medium was withdrawn and replaced with an equal volume of fresh medium. Drug quantitative analysis was performed as described above. Release profiles of free drugs are reported for comparison. Results are expressed as release \% over time \pm SD of three experiments.

Morphological studies. The morphology of the NPs dispersed in PBS pH 7.4 enriched with GSH $10 \mathrm{mM}$ was examined by TEM as described above.

FRET studies. Redox responsiveness of NPs was also evaluated by Förster resonance energy transfer (FRET) by co-encapsulating two different fluorescence probes (FRET pairs) into NP cores as described above. The hydrophobic dye DiO was chosen as the fluorescent donor and DiL as the acceptor molecule. FRET NPs were incubated in PBS with or without GSH $10 \mathrm{mM}$ ([NPs]=1 mg/mL) at $37^{\circ} \mathrm{C}$. The ratio between the maximum intensity of emission bands for DiL and $\mathrm{DiO}$ was monitored as function of time. Decrease of this ratio was considered indicative of NP aggregation or disassembly in the medium. Finally, fluorescence emission spectra of FRET NPs were collected at $\lambda_{\text {ex }} 488 \mathrm{~nm}$.

\section{Preparation of anticancer NPs}

DTX loaded NPs were prepared by the double emulsion-solvent evaporation method as previously described. In particular, before the emulsion processes, DTX $(0.1 \mathrm{mg})$ was 
dissolved in the DCM solution containing the polymer. Emulsion and purification of NPs were carried out as described before. Recovery yield of production process was evaluated by weighing the solid residue after freeze-drying. Results are expressed as the ratio of the actual NPs weight to the theoretical polymer weight $x 100$.

The hydrodynamic diameters $(\mathrm{DH})$, polydispersity indices (PDI) and zeta potentials of NPs were determined on a Zetasizer Nano ZS (Malvern Instruments Ltd.) as previously described. DTX loading inside NPs was assessed by dissolving $1 \mathrm{mg}$ of freeze-dried NPs in $1 \mathrm{~mL}$ of THF under stirring for $1 \mathrm{~h}$. Thereafter the sample was filtered through a $0.22 \mu \mathrm{m}$ filter and analyzed for DTX content by HPLC on a Shimadzu apparatus equipped with a LC10ADvp pump, a SIL-10ADvp autoinjector, a SPD-10Avp UV-Vis detector and a C-R6 integrator. The analysis was performed on a ACE $5 \mu \mathrm{m}$, C18 column $(250 \times 4.6 \mathrm{~mm}, \AA)$ (Phenomenex, USA). The mobile phase was a 40:60 (v/v) mixture of $20 \mathrm{mM}$ phosphate buffer at $\mathrm{pH} 4.5$ and acetonitrile pumped at a flow rate of $1 \mathrm{~mL} / \mathrm{min}$. The UV detector was set at $227 \mathrm{~nm}$. A calibration curve for DTX in THF was constructed in the concentration range $1-200 \mu \mathrm{g} / \mathrm{mL}$. The limits of quantitation (LOQ) and detection (LOD) in acetonitrile:water $50: 50(\mathrm{v} / \mathrm{v})$ were 1.29 and $0.39 \mu \mathrm{g} / \mathrm{mL}$.

In vitro release of DTX from NPs in PBS with or without GSH $10 \mathrm{mM}$ was investigated by a dialysis method. A known amount of NPs $(2 \mathrm{mg})$ was dispersed in $0.5 \mathrm{~mL}$ of PBS solution and placed in a dialysis bag $\left(\mathrm{MWCO}=3500 \mathrm{Da}\right.$, Spectra/Por $\left.{ }^{\circledR}\right)$. The sample was plunged in $8 \mathrm{~mL}$ of PBS (sink condition) and kept at $37^{\circ} \mathrm{C}$. At selected time intervals, $1 \mathrm{~mL}$ of release medium was withdrawn and replaced with an equal volume of fresh medium. DTX quantitative analysis was performed as described above. Release profile of the free drugs is reported for comparison. Results are expressed as release \% over time \pm SD of three experiments.

\section{Interactions with mucin}

The mucoadhesive tendency of NPs was investigated through turbidimetry, size and zeta potential measurements of NPs exposed to mucin. Mucin powder was dispersed in water $(0.08 \% \mathrm{w} / \mathrm{v})$ and stirred overnight. The dispersion was then centrifuged at $5000 \mathrm{rpm}$ for $20 \mathrm{~min}$ to collect the mucin-containing supernatant. Unloaded NPs (1 mg) were dispersed in $1 \mathrm{~mL}$ of mucin dispersion and the samples incubated at $37^{\circ} \mathrm{C}$ for $24 \mathrm{~h}$. At different time points $(0,1 \mathrm{~h}, 4 \mathrm{~h}$ and $24 \mathrm{~h})$, the turbidimetry of the mixtures was measured at $650 \mathrm{~nm}$ by spectrophotometry. Reference absorbance values of mucin and NP dispersions were also evaluated. The hydrodynamic diameter $\left(\mathrm{D}_{\mathrm{H}}\right)$, polydispersity index $(\mathrm{PI})$ and zeta potential of NPs were also assessed. The mucus-penetrating properties of fluorescent NPs through artificial mucus was investigated too. Briefly, $50 \mathrm{~mL}$ of artificial mucus was prepared adding $500 \mathrm{mg}$ DNA, $250 \mu \mathrm{L}$ of sterile egg yolk emulsion, $250 \mathrm{mg}$ of mucin, $0.295 \mathrm{mg}$ DTPA, 250 $\mathrm{mg}$ sodium chloride, $110 \mathrm{mg}$ potassium chloride and $1 \mathrm{~mL}$ of RPMl to $50 \mathrm{~mL}$ of water[30]. The dispersion was stirred until a homogenous mixture was obtained. Artificial mucus ( 0.5 $\mathrm{mL}$ ) was placed in the upper chambers of Transwell-24 well plates, whereas $1.5 \mathrm{~mL}$ of SILF was added in the lower chamber. Then, $0.1 \mathrm{~mL}$ of FRET-NPs water dispersion $(5 \mathrm{mg} / \mathrm{mL})$ was placed on the artificial mucus layer and maintained at r.t. At regular time points $(0,1 \mathrm{~h}$, $4 \mathrm{~h}$ and $24 \mathrm{~h}$ ), the acceptor medium was collected and fluorescence emission at $575 \mathrm{~nm}$ ( $\lambda_{\text {ex }}$ $488 \mathrm{~nm}$ ) was recorded on a Varian Cary Eclipse spectrophotometer using $1 \mathrm{~cm}$ path length 
quartz. Results are reported as percentage of NPs penetrated through artificial mucus layer. The hydrodynamic diameter $\left(\mathrm{DH}_{\mathrm{H}}\right)$ of NPs after penetration through the mucus was also assessed. As control, mucus-penetrating properties of FRET-NPs pretreated with GSH 10 $\mathrm{mM}$ for $1 \mathrm{~h}$ were evaluated too.

\section{Cell culture}

A549, Calu-3 and H1299 lung cancer cells were obtained from the American Type Culture Collection, cultured at $37^{\circ} \mathrm{C}$ in a humidified atmosphere containing $5 \% \mathrm{CO}_{2}$ and grown continuously in DMEM (A549 and Calu-3) or RPMI (H1299) supplemented with 10\% FBS, $100 \mathrm{unit} / \mathrm{mL}$ penicillin and $100 \mu \mathrm{g} / \mathrm{mL}$ streptomycin.

\section{MTS assay}

Cells $\left(2 \times 10^{4}\right)$ were placed in 96 well plates and cultured in $200 \mu \mathrm{L}$ of cell medium with or without FBS at $10 \%$. After $24 \mathrm{~h}$, cells were treated with unloaded NPs in the concentration range $0.01-50 \mathrm{mg} / \mathrm{mL}$. Cells treated with $0.1 \%(\mathrm{v} / \mathrm{v})$ Triton-X 100 and fresh media were used as a positive and a negative control, respectively. After $24 \mathrm{~h}$ of incubation, cells were washed with PBS and treated with CellTiter $96 \AA$ AQueous Cell Proliferation Assay $(20 \mu \mathrm{L}$ per well). After further incubation ( $3 \mathrm{~h}$ ), the absorbance was read at $490 \mathrm{~nm}$ in a microplate reader (Tecan Platereader, UK) and the percentage of metabolic activity (\%) calculated.

\section{Cell internalization studies}

Quantification of internalized NPs. The percentage of internalization of NPs was initially assessed in A549 cells. For these experiments, FRET NPs were employed. Cells were seeded in 24 wells/plate $\left(2 \times 10^{5}\right.$ cells/well) in $0.5 \mathrm{~mL}$ of DMEM supplemented with $10 \%$ FBS. After $24 \mathrm{~h}$ of growth at $37^{\circ} \mathrm{C}$, the cells were washed and incubated with $125 \mu \mathrm{g} / \mathrm{mL}$ of NPs, freshly re-suspended in milli $Q$ water and diluted in medium without Phenol Red and FBS. After different time points ( $1 \mathrm{~h}, 4 \mathrm{~h}$ and $24 \mathrm{~h}$ ), the media was collected and the fluorescence intensity of DiL was read at $575 \mathrm{~nm}\left(\lambda_{\text {ex }} 543 \mathrm{~nm}\right)$ in a microplate reader (Tecan Platereader, UK) for NP content. The concentration of NP in the extracellular compartment was calculated by means of a standard calibration curve derived for NP suspensions in the same cell media at known concentrations $(12.5-125 \mu \mathrm{g} / \mathrm{mL})$. The medium alone collected from untreated cells was used as control. Then, the amount and the \% of NP internalized were indirectly calculated.

FACS measurements. The entry of NPs into A549, Calu-3 and H1299 cells was also measured by FACS. For these experiments, FRET NPs were employed in order to evaluate the disassembly of NPs inside cells. Cells were seeded in 24 well plate $\left(2 \times 10^{5}\right.$ cells/well) in $0.5 \mathrm{~mL}$ of DMEM or RPMI 1640 media supplemented with $10 \%$ FBS. After $24 \mathrm{~h}$ of growth at $37^{\circ} \mathrm{C}$, the cells were washed and incubated for $1 \mathrm{~h}, 4 \mathrm{~h}$ and $24 \mathrm{~h}$ with $125 \mu \mathrm{g} / \mathrm{mL}$ of NPs, freshly re-suspended in milli $Q$ water and diluted in medium without $10 \%$ of FBS. After incubation with NPs, the cell monolayers were washed and detached from the plates with trypsin. Cells were centrifuged and re-suspended in PBS with Trypan Blue $0.4 \% \mathrm{v} / \mathrm{v}$. Finally, cells were fixed in FACS tubes in ice-cold PBS with $2 \%$ p-formaldehyde. DiO and DiL fluorescence was acquired by FACS using a Beckman Coulter Astrios EQ instrument. A blue laser at $488 \mathrm{~nm}\left(\lambda_{\mathrm{em}} 513 / 526 \mathrm{~nm}\right)$ and a yellow/green laser at $561 \mathrm{~nm}\left(\lambda_{\mathrm{em}} 579 / 616\right.$ 
$\mathrm{nm}$ ) were used as excitation source for the detection of DiO and DiL fluorescence, respectively. For FRET detection, the laser at $488 \mathrm{~nm}$ with $\lambda_{\text {em }} 576 / 621 \mathrm{~nm}$ was used. $10^{4}$ events/sample were acquired and analyzed with the Kaluza Analysis 1.3 Software.

FRET Imaging. A549 cells were incubated with FRET-NPs $125 \mu \mathrm{g} / \mathrm{mL}$ (in the cell culture media without FBS) at $37^{\circ} \mathrm{C}$ for $1 \mathrm{~h}, 4 \mathrm{~h}$ and $24 \mathrm{~h}$. Confocal imaging was performed using a Zeiss LSM 700 Confocal Laser Scanning Microscope equipped with Argon (488 nm) and $\mathrm{HeNe}(561,639 \mathrm{~nm})$ lasers and a 40X/1.2 NA water objective. FRET images were acquired with $\lambda_{\text {ex }} 488 \mathrm{~nm}$ and spectral filters of $505-530 \mathrm{~nm}$ and LP $560 \mathrm{~nm}$ for DiO and DiL detections. Zen 2009 image Software was utilized for image processing.

\section{Intracellular and extracellular responsiveness of NPs}

Intracellular NP reduction. A549 cells were seeded in 24 well plate $\left(2 \times 10^{5}\right.$ cells/well $)$ in $0.5 \mathrm{~mL}$ of DMEM supplemented with $10 \%$ FBS. After $24 \mathrm{~h}$ of growth at $37^{\circ} \mathrm{C}$, the cells were washed and incubated with $125 \mu \mathrm{g} / \mathrm{mL}$ of FRET-NPs, as described above. After $24 \mathrm{~h}$, the cells were washed in order to remove all the NPs not uptaken and incubated again for $48 \mathrm{~h}$ and $72 \mathrm{~h}$. Finally, cells were treated and the samples analysed by FACS as described above.

Extracellular mechanism of NP uptake. A549 cells were seeded in 24 well plate $(2 \mathrm{x}$ $10^{5}$ cells/well) in $0.5 \mathrm{~mL}$ of DMEM supplemented with $10 \% \mathrm{FBS}$. After $24 \mathrm{~h}$ of growth at $37^{\circ}$ $\mathrm{C}$, the cells were washed and pretreated with DTNB $2 \mathrm{mM}$ directly dissolved in serum-free medium for $30 \mathrm{~min}$, followed by incubation with $125 \mu \mathrm{g} / \mathrm{mL}$ of FRET-NPs in the presence of DTNB for $4 \mathrm{~h}$. After incubation, cells were treated and the samples analyzed by FACS as described above.

NP behavior in extracellular media. To determine the stability of NPs in the extracellular environment, $0.5 \mathrm{mg}$ of NPs were dispersed in $4 \mathrm{~mL}$ of fresh DMEM cell culture medium or conditioned medium containing biologically active components obtained from previously cultured A549 cells (contact time $1 \mathrm{~h}$ ) and incubated at $37^{\circ} \mathrm{C}$. Size measurements of the samples were taken after $1 \mathrm{~h}$ of incubation as described above.

Extracellular PEG release. Cells $\left(2 \times 10^{5}\right.$ cells/well) were placed in 24 well plate and cultured in $500 \mu \mathrm{L}$ of cell medium without FBS. After $24 \mathrm{~h}$, cells were treated with $1 \mathrm{mg} / \mathrm{mL}$ of unloaded NPs. At specific time points, the extracellular conditioned media was collected, filtrated and centrifuged at $17000 \mathrm{xg}$ for $30 \mathrm{~min}$. Finally, supernatants were collected and analyzed for PEG content through lodine assay. In detail, $50 \mu \mathrm{L}$ of the samples were added to $0.125 \mathrm{~mL}$ of barium chloride at $5 \% \mathrm{w} / \mathrm{v}$ and $0.125 \mathrm{~mL}$ of iodine solution $0.1 \mathrm{M}$. After 15 min of incubation, the absorbance of the samples was read at $490 \mathrm{~nm}$ in a microplate reader. The concentration of PEG was calculated by means of a standard calibration curve derived for PEG solution in cell media at known concentrations $(1-100 \mu \mathrm{g} / \mathrm{mL})$. The same conditioned medium alone treated with iodine was used as control.

\section{Spheroids culture}

Ultra low attachment (ULA) 96 well round bottom plates were employed for the culturing of HCT 116 and A549 spheroids. Cells grown as a monolayer were detached using trypsin then centrifuged, and the cell number was counted using a haemocytometer. Spheroids were seeded by diluting the single-cell suspensions in RPMI-1640 medium 
supplemented with $10 \%$ of FBS and 10000 cells per $\mathrm{ml}$ were added at a constant volume $(200 \mu \mathrm{l})$ per well in 96 well ULA plates. 6 wells containing the same concentration of cells were created for the experiments. The plates were centrifuged at $100 \mathrm{xg}$ for $4 \mathrm{~min}$.

\section{Uptake and distribution of NPs in cancer spheroids}

Spheroids were grown on ULA plates for 3 days to allow for compaction prior to use for the penetration and uptake studies. On day 3 of culture, the media was removed from the wells and replaced with $150 \mu \mathrm{l}$ media containing NPs (NP concentration $125 \mu \mathrm{g} / \mathrm{ml}$ ) and Hoechst $(0.1 \mu \mathrm{M})$ and were left to incubate for $24 \mathrm{~h}$. After incubation, the spheroids were transferred into $15 \mathrm{ml}$ Falcon conical tubes and washed twice with DPBS $(1 \mathrm{ml})$. Accutase $(1$ $\mathrm{ml}$ ) was then added and the tubes were incubated at $37^{\circ} \mathrm{C}$ for 5 min with agitation. The dissociation of spheroids was aided by mechanical pipetting. The spheroids were then centrifuged, fixed with $4 \%$ paraformaldehyde $(1 \mathrm{ml})$, washed with DPBS $(1 \mathrm{ml})$ and subsequently resuspended in DPBS $(0.3 \mathrm{ml})$ prior analysis by flow cytometry (MoFlo Astrios Cell sorter, Beckman Coulter). Cell separation and data analysis via FACS were by a published method[31].

\section{Statistical analysis}

Unless otherwise stated, all data are shown as mean \pm standard deviation (SD). Two way analysis of variance (ANOVA) was applied for comparison of three or more group means (Tukey's multiple comparisons test). $P$ value of $<0.05$ was considered statistically significant. ${ }^{* * * *},{ }^{* * *},{ }^{* *}$, and ${ }^{*}$ display $p<0.0001, p<0.001, p<0.01$, and $p<0.05$, respectively. GraphPad Prism 6 software was used for data analysis. 


\section{Results and Discussion}

The aim of this work was to design novel redox responsive PEGylated NPs intended for the local delivery of drugs to the lungs. To this purpose, NPs were designed around linear diblock copolymers of polyethylene glycol (PEG)-poly(lactic-co-glycolic acid) (PLGA), as PLGA cores can entrap different drugs, external hydrophilic PEG shells have been shown to promote NP transport through the lungs after inhalation [23, 32, 33] and PLGA-PEG micelles are well-established in clinical applications.[24] However, to introduce responsive functionality we aimed to install a disulfide linkage at a highly specific position between PLGA and PEG chains, in a manner similar to self-immolative linker strategies.[14, 34, 35] This was based on the criteria that the disulfide bond should be easily accessible to soluble GSH, and also that reduction should lead to the escape of the PEG layer into solution with concomitant formation of further active nucleophiles which could accelerate the degradation of the PLGA core. Since the tumor microenvironment can feature reactive thiols and reductive species both at extracellular / cell surface proximal sites as well as intracellular locations, we envisaged that the NPs would lose their stabilizing PEG regions through the cleavage of the disulfide bonds in the extracellular matrix of cancer tissue. In this way we aimed to promote the cellular uptake of the still intact PLGA NP cores, and then continue to degrade as they encountered further hydrolytic species inside the cancer cells.

\section{Synthesis and characterization of copolymers}

A linear diblock copolymer of PEG and PLGA containing a reducible disulfide linkage between PLGA and PEG chains was synthesized through a synthetic approach combining the ROP and the Aza-Michael Addition reaction. The synthesis was performed through three different steps (Fig. 1B): 1) synthesis of 2-((hydroxymethyl)disulfanyl)ethyl acrylate through the reaction of dithiodiethanol with acryloyl chloride; 2) ROP of lactide and glycolide monomers using 2-((hydroxymethyl)disulfanyl)ethyl acrylate as initiator, thus obtaining a PLGA-ss-ethyl acrylate (PLGA-SS); 3) Aza-Michael Addition between the terminal amine group of the mPEG $2 k$ and the acrylate group of the functionalized PLGA. All the synthetic steps led to high yields of products with few byproducts thus avoiding time-consuming purification stages. As control, a comparable non-responsive PLGA-PEG diblock copolymer without disulfide bonds, but with the same molecular weight, PEG /lactide/ glycolide molar ratio (table 1) as well as thermal properties (table S1) was synthesized (Fig. 1A). In this latter case, the copolymer was prepared by ROP of lactide and glycolide monomers initiated by $\mathrm{mPEG}{ }_{2 k}$ with $\mathrm{Sn}(\mathrm{Oct})_{2}$ as catalyst and the final structure was confirmed by ${ }^{1} \mathrm{H}-,{ }^{13} \mathrm{C}-\mathrm{NMR}$ and AT-IR[36].

2-((Hydroxymethyl)disulfanyl)ethyl acrylate was accordingly obtained and confirmed as previously reported [37]. Addition of DL-lactide and glycolide to 2((hydroxymethyl)disulfanyl)ethyl acrylate in the presence of $\mathrm{Sn}(\mathrm{Oct})_{2}$ as catalyst resulted in ROP of the monomers initiated from the hydroxyl terminus. ${ }^{1} \mathrm{H}-\mathrm{NMR}$ spectra showed the expected resonances of the polymer backbone at $\delta=1.57-1.61 \mathrm{ppm}$ and $\delta=5.20-5.26 \mathrm{ppm}$ (methane and methyl protons of poly(lactic acid)) and at $\delta=4.70-4.93 \mathrm{ppm}$ (methylene group of poly(glycolic acid)). The presence of the terminal acryl group was confirmed by the protons between $\delta=5$ and $\delta=7 \mathrm{ppm}$. The conjugation of PEG block to the PLGA-SS was 
finally carried out through Aza-Michael addition in a single synthetic step with simple purification. The structure of the diblock copolymer was confirmed by ${ }^{1} \mathrm{H}-\mathrm{NMR}$ spectra[38] according to the peaks at $\delta=1.57-1.61 \mathrm{ppm}$ and $\delta=5.17-5.27 \mathrm{ppm}$ (poly(lactic acid)), at $\delta=$ 4.79-4.93 ppm (poly(glycolic acid)), at $\delta=3.40$ and $\delta=3.66-3.68 \mathrm{ppm}$ (polyethylene glycol). Signals corresponding to the acrylate vinylic protons between $\delta=5$ and $\delta=7 \mathrm{ppm}$ were not apparent after reaction, which indicated the complete addition between PLGA/PEG blocks. The $\mathrm{Mn}_{\mathrm{n}}$ of copolymers and the ratios of each block (lactide, glycolide and PEG chains), were determined by relative peak integrals of PLGA and PEG proton resonances and confirmed by GPC measurements (table 1). In fact, SEC traces of both copolymers (Fig. S3) demonstrate no presence of free PEG in the final products. Hydrophilic/hydrophobic properties of intermediates and copolymers were also evaluated by contact angle measurements (table S1), thus indicating the effectiveness of the reactions.

\section{Preparation and characterization of NPs}

PLGA-PEG and PLGA-S-S-PEG block copolymers were employed to prepare nonredox responsive and redox responsive NPs (nRR-NPs and RR-NPs), respectively (Fig. 2A). NPs were prepared by double emulsion-solvent evaporation techniques and characterized in terms of particle size and polydispersity and zeta potential (Fig. 2B-D). The recovery yield for the formulations was very high $(\sim 75 \%)$ indicating that neither polymer precipitation nor NP aggregation occurred during preparation. Furthermore, similar colloidal properties of both NPs were found, thus highlighting a comparable behaviour of the copolymers. NPs exhibited hydrodynamic diameters around $120 \mathrm{~nm}$, low size polydispersity index and high negative zeta potential values.

Exploiting the well known versatility of PLGA-based block copolymers and modulating the processing parameters of the emulsification-solvent evaporation technique [39], we performed a preliminary encapsulation study aimed at elucidating NP potential to deliver both hydrophilic and hydrophobic compounds with comparable molecular weight, alone and/or in association. In particular, Rhod6G and Fluo were selected as hydrophilic drug models and dissolved in the internal water phase during NP preparation, whereas DiO and DiL (FRET pairs molecules) were selected as hydrophobic probes and co-solubilized with the copolymers in the organic phase. As summarized in table S2, the formulation processes, NP size, polydispersity index and as well as zeta potential values, were not significantly influenced by drug entrapment or drug type. At the same time, in all cases, we obtained a high entrapment efficiency of the different compounds inside NPs, without observing any effect of copolymer type (Fig. 2C).

To compare the PEG shells thickness on the nRR- and RR-NPs, Fixed Aqueous Layer Thickness (FALT) measurements and stability studies in different simulated biological fluids were performed. FALT of the outer PEG shell of NPs was determined by measuring $\zeta$ of NPs as a function of electrolyte concentration. The increase of ionic strength, in fact, induced a decrease of $\zeta$ as a result of the variation of the slipping plane of the PEG fringe away from the surface of NP core [27]. As reported in Fig. 2D, the slope value of the linear regression line obtained plotting Log $\zeta$ vs sodium chloride concentration gives shell thickness $(\mathrm{nm})$. Formulated by copolymers with comparable molecular weight and 
PLGA/PEG molar ratio, and showing as well as same size, nRR- and RR-NPs did not show any significant difference in terms of PEG shell thickness $(1.2 \mathrm{~nm})$. Both systems showed a good colloidal stability in PBS and in $\mathrm{NaCl} 0.9 \%$ w/v (Fig. 2E) up to 3 days of incubation, as indicated by the absence of macroscopic aggregates and retention of 'original ' particle size. The stability of the systems in Simulated Lung Interstitial Fluids (SILF) was also satisfactory over extended time periods (Fig. 2E).

\section{Redox responsiveness of NPs}

In order to investigate the redox responsiveness of NPs in a simulated reductive environment, stability, release, morphological study and FRET experiments were performed. As clearly evidenced in Fig. 3A, RR-NPs showed low colloidal stability under different in vitro reducing conditions (GSH and DTT $10 \mathrm{mM}$ ), highlighted by the change of initial particle size and shape of size distribution curves, compared to nRR-NPs. These results indicated a fast aggregation or a disassembly of RR-NPs structure within 30 min through the reduction of the disulfide bond in the copolymer chains and the cleavage of the link between PLGA and PEG blocks. Changes in the shape of particle size distribution profile indicate formation of species with appearance of different subpopulations which may indicate lose of original species and appearance of aggregates, potentially formed from partly degraded RR-NPs following loos of stabilizing PEG layer and PLGA matrix degradation. Comparable results were found when incubating NPs in GSH and DTT ranging from 5 to $20 \mathrm{mM}$ at different time points until $24 \mathrm{~h}$ of incubation (data not shown). These data are in line with the morphological analysis of NPs at both nanoscale and macroscale levels in the same conditions. As illustrated in Fig. 3C, TEM images of RR-NPs dispersed in PBS without reductive agents showed the spherical morphology and the absence of aggregation of NPs comparable to nRR-NPs, with a size in line with the data obtained by DLS. After incubation with GSH, a strong deformation of NP shape can be seen, with appearance of aggregated clusters. Degradation of RR-NPs is also evident at a macroscopic level (Fig. 3D).

Finally, redox-triggered drug release from NPs was demonstrated through release studies of Rhod6G-loaded NPs dispersed in PBS at pH 7.4 with and without GSH $10 \mathrm{mM}$ (Fig. 3B). Results showed a sustained release of Rhod6G from RR-NPs in PBS, comparable to nRR-NPs. In contrast, with the addition of GSH as triggering agent in the releasing medium, a fast Rhod6G release from RR-NPs, completed after $24 \mathrm{~h}$ of incubation, was found, thus suggesting a rapid disassembly of NP structure as a consequence of PEG cleavage and accelerated PLGA degradation.

To confirm these data, FRET studies of NPs loaded simultaneously with DiO and DiL probes were carried out. FRET is a mechanism describing energy transfer between two light-sensitive molecules, a donor chromophore and an acceptor. The efficiency of this energy transfer is inversely proportional to the sixth power of the distance between donor and acceptor, making FRET extremely sensitive to small changes in distance. Measurement of FRET efficiency is a useful tool to determine if two fluorophores are loaded inside a NP system and to monitor its self-assembly and disassembly behaviour in different biological conditions and cell models as well as cargo release from NPs [40]. As donor and acceptor, 
we chose the hydrophobic dyes DiO and DiL respectively, since DiO emission spectrum ( $\lambda_{\mathrm{ex}}$ / $\lambda_{\mathrm{em}}$ at $\left.488 / 505 \mathrm{~nm}\right)$ overlaps well with the DiL absorption spectrum ( $\lambda_{\mathrm{ex}} / \lambda_{\mathrm{em}}$ at 543 / 575 $\mathrm{nm})$.

Excitation at $488 \mathrm{~nm}$ of NPs coencapsulating the two chromofluorogenic components and dispersed in water showed that the DiL emission at $575 \mathrm{~nm}$ dominated over the emission of the DiO at $505 \mathrm{~nm}$ (Fig. 4A). The intense fluorescence of DiL demonstrates that efficient energy transfer occurred, attributable to the close proximity of the co-encapsulated compounds in NPs core matrix. However, solubilizing the same formulation in organic solvent (DCM) disrupted its core-shell structure, releasing the fluorophores to the external medium, reflected in a marked reduction in FRET efficiency ratio (I575/505 reduced from 3.5 to 0.8 ). On this basis, we monitored the reduction in FRET efficiency of NPs incubated in PBS pH 7.4 with or without GSH $10 \mathrm{mM}$. Emission spectra of FRET NPs after excitation at $488 \mathrm{~nm}(\lambda$ ex DIO) are reported in Figure 4B. After $4 \mathrm{~h}$ of incubation of RR-NPs in PBS enriched with GSH $10 \mathrm{mM}$, we observed a strong decrease of DiL emission in comparison with all the other samples, although the increase of DiO emission was not detected most likely due to its insolubility and aggregation in aqueous media (unlike its solubility in DCM in the profile in figure A). From these spectra, then FRET efficiency ratio was calculated (Fig. 4C). No significant difference in FRET efficiency ratio was observed for nRR-NPs in both conditions up to $24 \mathrm{~h}$ of incubation. As described above, for RR-NPs, the addition of GSH led to a strong decrease in DIL emission and consequently decreased FRET efficiency ratio (I575/505 decreased from 3.5 to 2.1), thus highlighting a progressive release of the dyes from NP core, following exposure to GSH and their loos of matrix integrity. No interference between the dyes and the thiols of GSH and neither eventual degradation of the dyes was found, as shown in Fig. S4, thus confirming a FRET related dissociation of the dyes in a reductive environment. In particular, we have performed as control some fluorescent experiments with the dyes alone and in association in the presence of GSH $10 \mathrm{mM}$. No modification in the emission spectra of DiO at $\lambda_{\text {ex }} 488$, DiL at $\lambda_{\text {ex }} 543$ and DiO/DiL mixture (FRET effect) at $\lambda_{\text {ex }} 488$ was observed.

\section{Preparation of anticancer NPs}

Since the NPs have been developed for a potential anticancer application, Docetaxel (DTX), a lipophilic anticancer drug approved for lung cancer treatment was loaded inside NPs at $10 \%$ compared to copolymer weight. In figure 5A, properties of DTX-loaded NPs are shown, in terms of size, polydispersity index, yield of the preparation, surface charge and drug loading. In this context, nRR-NPs and RR-NPs showed similar entrapment ability of DTX, as for the other drug models previously tested. At the same time, release studies of DTX from NPs by dialysis were in line with the results obtained from NPs loaded with Rhodamine 6G. In figure 5B, in fact, it is possible to note that PLGA-S-S-PEG NPs displayed a sustained release pattern of DTX in PBS, comparable to PLGA-PEG NPs in the same acceptor medium, which was unaffected by the presence of reductive agents. In particular, around the $50 \%$ of the entrapped DTX was released in 14 days, compared with the free drug in the same conditions (inset). On the contrary, with the addition of GSH in the releasing 
medium, a fast drug release from PLGA-S-S-PEG, completed after 3 days of incubation, was found.

\section{Interactions with mucus}

A key parameter to consider in the case of inhalation therapies is the ability to overcome the biological barriers imposed by lungs, especially the mucus barrier, which reduces the chances of NPs to reach epithelial cells. Accordingly, NPs were assessed for their abilities to interact with an artificial mucus layer, in terms of both mucoadhesive and mucus-penetrating properties. Mucoadhesion studies were performed by measuring the turbidity at $650 \mathrm{~nm}$ (Fig. 6A), as well as size and zeta potential values (Fig. 6B) of NP dispersions in mucin solutions over time. As evidenced in the graphs, all the experiments showed no interaction between both NP systems and mucin up to $24 \mathrm{~h}$ of incubation. As expected, the presence of PEG shell allowed a time dependent NP penetration through the artificial mucus layer, in line with previous studies on NPs with low MW PEG coatings [41]. In fact, a high percent of still intact fluorescent NPs, co-loaded with DiO and DiL probes, was found in the acceptor medium after $24 \mathrm{~h}$ (Fig. 6C). In order to discriminate NPs from the loaded dyes that could be released, we exploited the FRET mechanism, as described above, thus demonstrating that NP structure integrity was still intact after permeation, and the unchanged FRET profiles in (Fig. 6E), as well as by the size distribution curves of collected NPs dispersed in the SILF medium (Fig. 6D). To confirm the role of PEG in NP penetration through the artificial mucus, the experiment was performed also with NPs pretreated with GSH as control. In figure S5, as expected no significant differences in the spectra of nRR-NPs pre-treated with GSH was found. On the contrary, following GSH treatment and the subsequent release of PEG shedding from RR-NPs, a marked reduction of penetration extent of RR-NPs was observed through the quenching of the FRET emission spectra.

\section{Cellular uptake studies}

In order to investigate the internalization of NPs into cancer cells we carried out uptake experiments of labeled NPs in different lung cancer cell lines. To this aim, we again employed FRET NPs. By monitoring FRET it was possible to follow the cellular internalization, to assess stability and NP integrity after cell internalization, as well as to 'model' drug release over time. The experiment was performed at $1 \mathrm{~h}, 4 \mathrm{~h}$ and $24 \mathrm{~h}$ with both RR-NPs and nRR-NPs, applied at $125 \mu \mathrm{g} / \mathrm{mL}$, which was shown to be a concentration well tolerated by cells (Fig. S6).

Initial experiments quantified the amount of NPs internalized by A549 cells in terms of percentage of the applied dose (Fig. 7A). A significantly higher uptake of RR-NPs in comparison with nRR-NPs was shown at all the incubation times. In fact, after $1 \mathrm{~h}$ of incubation, $13 \%$ and $30 \%$ of applied nRR-NPs and RR-NPs, respectively, entered the A549 cells, increasing to around $55 \%$ and $90 \%$, respectively, after $24 \mathrm{~h}$.

FACS measurements and confocal imaging were performed to further investigate the uptake rate and the fate of NP after internalization. To establish appropriate experimental conditions to measure FRET signals by FACS, we first analysed cells treated with DiO and DiL either individually or in combination, according the method of Banning et al [42]. Gating 
was applied to living cells according to forward and sideward scatter (FSC/SSC) and adjusted photomultiplier tube voltages and compensation for $\mathrm{DiO}$ and $\mathrm{DiL}$ to specifically assess FRET in double positive cells. Thus, via excitation at $488 \mathrm{~nm}$ and employing emission filters at 576/621 nm, FRET was plotted against DiL and a gate was introduced to determine the amount of FRET-positive cells. This gate was adjusted to FRET-negative cells treated with $\mathrm{DiL}$ and DiO alone. In figure 7B, the mean fluorescent intensities (MFI) of DiL and FRET of A549 cells after treatment with NPs at different times, are represented. Through DiL emission analysis $\left(\lambda_{\text {ex }} 561 \mathrm{~nm}-\lambda_{\text {em }} 579 / 616 \mathrm{~nm}\right.$ ), we monitored the uptake rate from the cells of the drug model, both delivered from NPs as well as eventually released from them. Also in this case, we observed a significantly higher uptake of DiL loaded in RR-NPs in comparison with nRR-NPs, especially after $4 \mathrm{~h}(0.5$ and $1.5 \mathrm{MFI}$ for nRR-NPs and RRNPs respectively) and $24 \mathrm{~h}$ of treatment (around 2 and $9 \mathrm{MFI}$ for nRR-NPs and RR-NPs respectively). Thus considering the MFI of FRET, we have an indication of the amount of intact NPs internalized by cells. Again, we found that uptake of RR-NPs was much more pronounced than nRR-NPs especially after $24 \mathrm{~h}$ of time contact $(0.2$ and $0.6 \mathrm{MFI}$ for nRRNPs and RR-NPs respectively). Comparable results were obtained in $\mathrm{H} 1299$ cells (Fig. S7B). Although the same trends in terms of internalization of nRR-NPs compared to RRNPs were found, there were differences in overall FRET MFI over short incubation times in the case of Calu-3 cells (Fig. S7A), probably due differences in the cell line attributes [43]. Results obtained by FACS were confirmed by confocal imaging. In the case of A549 cells (Fig. 7C), after $1 \mathrm{~h}$ of incubation with NPs, yellow fluorescence was observed in the cell interiors, produced by the FRET mechanism between DiO and DiL. The intensity of fluorescence was greater for cells treated with RR-NPs compared to nRR-NPs, indicative of higher overall uptake. This effect was more evident after $4 \mathrm{~h}$ and $24 \mathrm{~h}$ of incubation. Additionally, in the case of RR-NPs, an increase in DiO green fluorescence was observable with time, suggesting the release of the dyes following faster intracellular redox- responsive disassembly of the RR-NP cores.

To further validate the exploitation of the FRET mechanism related to the colocalization of the probes inside NPs at cell level, we carried out a preliminary study as control with a cell membrane model as previously reported[40]. Small unilamellar vesicles (SUV) were employed as a membrane model and prepared as reported by Li et al [44]. FRET NPs or the free probes $(0.6 \mathrm{mg} / \mathrm{mL})$ were mixed with the SUV solution $(2 \mathrm{mg} / \mathrm{mL})$ in order to examine the release of the probes from NPs to lipid bilayers. At different time points, fluorescence emission spectra (lex 488) were recorded and the $\mathrm{IF}_{575 / 505}$ calculated as indication of the FRET efficiency. In figure S8, it is clearly evident that a decrease of FRET occurred over time for the free dyes due to their partition in the membrane bilayer, as expected from prior literature[40]. In contrast, FRET NPs showed the same spectra and the same FRET efficiency at all time points tested, thus indicating no release of the entrapped dyes outside the cells.

The higher and faster uptake of RR-NPs, in comparison with nRR-NPs, in the different cell lines after short incubation times, could be attributed to an initial extracellular reduction of the linkage between the PLGA core and the PEG shell, in line with work published for analogous DNA-releasing polymers. [19] In our case this reduction was likely to lead to shedding of some of the PEG layer, consequently reducing the 'steric' barrier to cell internalization[45]. It has previously been shown that PEG-poly(lactide) co-polymers, with oligo-cysteine cross-links which stabilized micellar structures, were internalized more 
efficiently than non-cross-linked PEG-poly(lactide) micelles, indicating that structural integrity of NPs is important in cell internalization [46]. Thus, the PEG shell in our block copolymers was key to initial colloidal stability, but removal of, at least some of this shell, was likely to have been critical in enhancing the cell membrane interaction and subsequent cell entry. In this context we noted, a comparable stability of the RR-NPs and nRR-NPs systems in cell culture media with or without the presence of serum (Fig. S9).

\section{Intracellular and extracellular responsiveness of NPs}

To investigate further the different intracellular responsiveness of NPs to redox mechanisms, uptake experiments of NPs into A549 cells were carried out over $24 \mathrm{~h}$ of incubation and the FRET effect monitored. In figure $8 \mathrm{~A}$, the percentage of FRET-positive cells and the ratio between the MFI of FRET ( $\lambda_{\text {ex }} 488 \mathrm{~nm}-\lambda_{\text {em }} 576 / 621 \mathrm{~nm}$ ) and DiO ( $\lambda_{\text {ex }} 488$ $\mathrm{nm}-\lambda_{\mathrm{em}} 513 / 526 \mathrm{~nm}$ ) are reported. After internalization of nRR-NPs and RR-NPs, the number of FRET-positive cells decreased by $20 \%$ (from $40 \%$ to $32 \%$ ) and $50 \%$ (from $40 \%$ to $20 \%$ ) respectively. At the same time the FRET/DiO MFI ratio of cells treated with nRRNPs did not show any change over time, whereas a strong decrease of this value was evident in the case of cells treated with RR-NPs. This indicated the decrease of the FRET effect, as well as the increase of DiO signals, due to the faster disassembly of NPs within the intracellular space.

To test if extracellular reductive mechanisms were involved in the different internalization rates of NPs, uptake studies of FRET NPs in the presence of DTNB were carried out. DTNB is a cell impermeable agent but reacts with free thiols thus blocking the action of any free sulfhydryls present in the extracellular environment. These experiments showed that DTNB did not cause any modification in the cellular uptake of nRR-NPs, relative to DTNB free conditions (Fig. 8B), but produced a strong decrease of RR-NP uptake. This decrease was observed both in terms of DiL MFI as well as FRET/DiO MFI ratio, and the values obtained were comparable to the control formulation. Finally, to confirm the extracellular responsiveness of the carrier, colloidal stability studies of NPs in conditioned cell medium and PEG release rate in the extracellular compartment were conducted. Firstly, NPs were dispersed in the conditioned medium employed to grow A549 cells for $4 \mathrm{~h}$. After $1 \mathrm{~h}$ of incubation, RR-NPs were no longer colloidally stable, compared to nRR-NPs and to the same carrier dispersed in fresh cell culture medium (Fig. 8C). At the same time, a much faster PEG release from RR-NPs in the extracellular compartment of cancer cell cultures was found (Fig. 8D). In particular, we found in the cell media around $15 \%$ and $40 \%$ of PEG released compared to the applied doses for nRR-NPs and RR-NPs respectively, after $4 \mathrm{~h}$ of treatment. Taken together, these results demonstrated the effective responsiveness of RRNPs to the specific extracellular environment, which we attribute to the accessibility to cellsecreted thiolated species of the disulfide bonds between the PLGA and PEG copolymer moieties. In turn, the breaking of these links led to release of PEG chains and subsequent enhanced NP hydrophobicity, which was manifest by colloidal instability, and enhanced internalization of NPs by the cells in culture. 


\section{Uptake and distribution of NPs in cancer spheroids}

With the aim to investigate further the potential of NPs to penetrate cancer tissues, 3Dspheroids models of HCT 116 and A549 cancer cells were employed[31]. The morphology of the 3D- cell spheroids is shown in Fig. 9. In this experiment, we employed $125 \mu \mathrm{g} / \mathrm{mL}$ of FRET NPs in a $24 \mathrm{~h}$ treatment. As depicted in Fig. 9, in both spheroid models, RR-NPs showed better penetration, compared to nRR-NPs, reaching all spheroid regions, the outer rim of proliferating cells, the middle viable layer of quiescent cells, but also the internal necrotic core of the spheroid, as judged from the comparisons with penetration of the standard probe[31]. The difference in nRR-NPs and RR-NPs penetration could again be attributed to the cleavage of the PEG shell of the RR-NPs formulation in the extracellular environment of the spheroid and hence improved cellular internalization; consistent with the data on cellular uptake in $2 \mathrm{D}$ cell monolayers. The data hence suggested that the RR-NPs retained an ability to permeate through the cancer cell aggregates, as well as promoting deeper penetration into avascular cancerous sites.

\section{Conclusions}

A new linear and amphiphilic diblock copolymer containing a reducible disulfide bridge specifically located via ethanoate ester links between poly(lactic-co-glycolic acid) (PLGA) and polyethylene glycol (PEG) blocks was synthesized. The polymer was employed to form redox responsive nanoparticles which exhibited ability to penetrate mucus layer and high colloidal stability in simulated biological fluids. However a fast disassembly/aggregation of NPs in conditions simulating intracellular reductive environment was found. Cellular internalization studies performed in in vitro 2D- and 3D- lung cancer models, indicated enhanced internalization of the redox-responsive NPs, compared to nRR-NP analogues without the disulfide link between PLGA and PEG, which we suggest arises from a double redox responsive behaviour of the NPs via loss of colloidally-stabilising PEG chains in the region of cancer cell surfaces, as well as the enhanced intracellular breakdown of the particles due to cytosolic reduction. We suggest that the chemical design principles of placing the reductively-cleavable linker via a critical ethanoate ester spacer between the hydrophilic and hydrophobic regions of this polymer, coupled with the mucus penetrating properties of short/medium PEG chains and the well-established regulatory profile of PLGA blocks, renders our approach promising for future in vivo applications. These experiments are in progress.

\section{Acknowledgments}

Claudia Conte was supported by a fellowship by Associazione Italiana per la Ricerca sul Cancro (AIRC) co-funded by the European Union (iCARE/Marie Curie 2014). CA thanks the Engineering and Physical Sciences Research Council (EPSRC: Grants EP/H005625/1, EP/J021180/1, EP/I01375X/1 and EP/N03371X/1) and the Royal Society for a Wolfson 
Research Merit Award (WM150086). We also thank Tom Booth, Paul Cooling, Esme Ireson and Christine Grainger-Boultby for technical support.

\section{Data access statement}

All raw data created during this research are openly available from the corresponding author cameron.alexander@nottingham.ac.uk) and at the University of Nottingham Research Data Management Repository (https://rdmc.nottingham.ac.uk/) and all analysed data supporting this study are provided as $\mathrm{ESI}{ }^{\dagger}$ accompanying this paper.

\section{References}

[1] A. Kuzmov, T. Minko, Nanotechnology approaches for inhalation treatment of lung diseases, Journal of Controlled Release, 219 (2015) 500-518.

[2] J.S. Patton, P.R. Byron, Inhaling medicines: delivering drugs to the body through the lungs, Nat Rev Drug Discov, 6 (2007) 67-74.

[3] C.A. Ruge, J. Kirch, C.M. Lehr, Pulmonary drug delivery: from generating aerosols to overcoming biological barriers-therapeutic possibilities and technological challenges, The Lancet. Respiratory medicine, 1 (2013) 402-413.

[4] P. Zarogoulidis, E. Chatzaki, K. Porpodis, K. Domvri, W. Hohenforst-Schmidt, E.P. Goldberg, N. Karamanos, K. Zarogoulidis, Inhaled chemotherapy in lung cancer: future concept of nanomedicine, International Journal of Nanomedicine, 7 (2012) 1551-1572.

[5] I. d'Angelo, C. Conte, A. Miro, F. Quaglia, F. Ungaro, Pulmonary Drug Delivery: A Role for Polymeric Nanoparticles?, Current Topics in Medicinal Chemistry, 15 (2015) 386-400.

[6] Q. Xu, L.M. Ensign, N.J. Boylan, A. Schon, X. Gong, J.C. Yang, N.W. Lamb, S. Cai, T. Yu, E. Freire, J. Hanes, Impact of Surface Polyethylene Glycol (PEG) Density on Biodegradable Nanoparticle Transport in Mucus ex Vivo and Distribution in Vivo, ACS nano, 9 (2015) 9217-9227. [7] P. Mastorakos, A.L. da Silva, J. Chisholm, E. Song, W.K. Choi, M.P. Boyle, M.M. Morales, J. Hanes, J.S. Suk, Highly compacted biodegradable DNA nanoparticles capable of overcoming the mucus barrier for inhaled lung gene therapy, Proceedings of the National Academy of Sciences of the United States of America, 112 (2015) 8720-8725.

[8] S. Mura, J. Nicolas, P. Couvreur, Stimuli-responsive nanocarriers for drug delivery, Nature Materials, 12 (2013) 991-1003.

[9] J.Z. Du, L.A. Lane, S.M. Nie, Stimuli-responsive nanoparticles for targeting the tumor microenvironment, Journal of Controlled Release, 219 (2015) 205-214.

[10] S. Ganta, H. Devalapally, A. Shahiwala, M. Amiji, A review of stimuli-responsive nanocarriers for drug and gene delivery, Journal of Controlled Release, 126 (2008) 187-204.

[11] V.P. Torchilin, Multifunctional, stimuli-sensitive nanoparticulate systems for drug delivery, Nat Rev Drug Discov, 13 (2014) 813-827.

[12] R. Cheng, F. Feng, F.H. Meng, C. Deng, J. Feijen, Z.Y. Zhong, Glutathione-responsive nanovehicles as a promising platform for targeted intracellular drug and gene delivery, Journal of Controlled Release, 152 (2011) 2-12.

[13] A.O. Saeed, J.P. Magnusson, E. Moradi, M. Soliman, W.X. Wang, S. Stolnik, K.J. Thurecht, S.M. Howdle, C. Alexander, Modular Construction of Multifunctional Bioresponsive Cell-Targeted Nanoparticles for Gene Delivery, Bioconjugate Chemistry, 22 (2011) 156-168.

[14] A.R. Khan, J.P. Magnusson, S. Watson, A.M. Grabowska, R.W. Wilkinson, C. Alexander, D. Pritchard, Camptothecin prodrug block copolymer micelles with high drug loading and target specificity, Polymer Chemistry, 5 (2014) 5320-5329. 
[15] G. Saito, J.A. Swanson, K.D. Lee, Drug delivery strategy utilizing conjugation via reversible disulfide linkages: role and site of cellular reducing activities, Advanced Drug Delivery Reviews, 55 (2003) 199-215.

[16] M. Sun, K. Wang, D. Oupicky, Advances in Stimulus-Responsive Polymeric Materials for Systemic Delivery of Nucleic Acids, Advanced healthcare materials, (2017).

[17] X.Y. Zhang, L. Han, M.Y. Liu, K. Wang, L. Tao, Q. Wan, Y. Wei, Recent progress and advances in redox-responsive polymers as controlled delivery nanoplatforms, Mat Chem Front, 1 (2017) 807822.

[18] N.K. Damle, P. Frost, Antibody-targeted chemotherapy with immunoconjugates of calicheamicin, Current opinion in pharmacology, 3 (2003) 386-390.

[19] W.C. Sun, P.B. Davis, Reducible DNA nanoparticles enhance in vitro gene transfer via an extracellular mechanism, Journal of Controlled Release, 146 (2010) 118-127.

[20] E.P. Feener, W.C. Shen, H.J.P. Ryser, Cleavage of Disulfide Bonds in Endocytosed Macromolecules - a Processing Not Associated with Lysosomes or Endosomes, Journal of Biological Chemistry, 265 (1990) 18780-18785.

[21] R. Mandel, H.J. Ryser, F. Ghani, M. Wu, D. Peak, Inhibition of a reductive function of the plasma membrane by bacitracin and antibodies against protein disulfide-isomerase, Proceedings of the National Academy of Sciences of the United States of America, 90 (1993) 4112-4116.

[22] K.Y. Kwok, D.L. McKenzie, D.L. Evers, K.G. Rice, Formulation of highly soluble poly(ethylene glycol)-peptide DNA condensates, Journal of pharmaceutical sciences, 88 (1999) 996-1003.

[23] C. Conte, I. d'Angelo, A. Miro, F. Ungaro, F. Quaglia, PEGylated Polyester-Based Nanoncologicals, Current Topics in Medicinal Chemistry, 14 (2014) 1097-1114.

[24] C. Oerlemans, W. Bult, M. Bos, G. Storm, J.F.W. Nijsen, W.E. Hennink, Polymeric Micelles in Anticancer Therapy: Targeting, Imaging and Triggered Release, Pharmaceutical Research, 27 (2010) 2569-2589.

[25] J.H. Jeong, D.W. Lim, D.K. Han, T.G. Park, Synthesis, characterization and protein adsorption behaviors of PLGA/PEG di-block co-polymer blend films, Colloids and surfaces. B, Biointerfaces, 18 (2000) 371-379.

[26] C.Y. Hong, Y.Z. You, D.C. Wu, Y. Liu, C.Y. Pan, Thermal control over the topology of cleavable polymers: from linear to hyperbranched structures, Journal of the American Chemical Society, 129 (2007) 5354-5355.

[27] T.K. Endres, M. Beck-Broichsitter, O. Samsonova, T. Renette, T.H. Kissel, Self-assembled biodegradable amphiphilic PEG-PCL-IPEI triblock copolymers at the borderline between micelles and nanoparticles designed for drug and gene delivery, Biomaterials, 32 (2011) 7721-7731.

[28] C. Conte, I. Fotticchia, P. Tirino, F. Moret, B. Pagano, R. Gref, F. Ungaro, E. Reddi, C. Giancola, F. Quaglia, Cyclodextrin-assisted assembly of PEGylated polyester nanoparticles decorated with folate, Colloids and Surfaces B-Biointerfaces, 141 (2016) 148-157.

[29] M.R.C. Marques, R. Loebenberg, M. Almukainzi, Simulated Biological Fluids with Possible Application in Dissolution Testing, Dissolution Technologies, 18 (2011) 15-28.

[30] F. Ungaro, I. d'Angelo, C. Coletta, R. d'Emmanuele di Villa Bianca, R. Sorrentino, B. Perfetto, M.A. Tufano, A. Miro, M.I. La Rotonda, F. Quaglia, Dry powders based on PLGA nanoparticles for pulmonary delivery of antibiotics: modulation of encapsulation efficiency, release rate and lung deposition pattern by hydrophilic polymers, Journal of controlled release : official journal of the Controlled Release Society, 157 (2012) 149-159.

[31] A. Tchoryk, Ph.D. Thesis, in: University of Nottingham 2017, http:://eprints.nottingham.ac.uk/ethesis/.

[32] P. Muralidharan, M. Malapit, E. Mallory, D. Hayes, H.M. Mansour, Inhalable nanoparticulate powders for respiratory delivery, Nanomedicine-Nanotechnology Biology and Medicine, 11 (2015) 1189-1199.

[33] S.K. Lai, Y.Y. Wang, J. Hanes, Mucus-penetrating nanoparticles for drug and gene delivery to mucosal tissues, Advanced Drug Delivery Reviews, 61 (2009) 158-171. 
[34] A. Kock, K. Zuwala, A.A.A. Smith, P. Ruiz-Sanchis, B.M. Wohl, M. Tolstrup, A.N. Zelikin, Disulfide reshuffling triggers the release of a thiol-free anti-HIV agent to make up fast-acting, potent macromolecular prodrugs, Chemical Communications, 50 (2014) 14498-14500.

[35] M. Avital-Shmilovici, D. Shabat, Self-immolative dendrimers: A distinctive approach to molecular amplification, Soft Matter, 6 (2010) 1073-1080.

[36] Y. Yu, Z. Pang, W. Lu, Q. Yin, H. Gao, X. Jiang, Self-assembled polymersomes conjugated with lactoferrin as novel drug carrier for brain delivery, Pharmaceutical research, 29 (2012) 83-96.

[37] F. Chen, J. Zhang, Y. He, X. Fang, Y. Wang, M. Chen, Glycyrrhetinic acid-decorated and reduction-sensitive micelles to enhance the bioavailability and anti-hepatocellular carcinoma efficacy of tanshinone IIA, Biomaterials science, 4 (2016) 167-182.

[38] X. Liu, N. Huang, H. Wang, H. Li, Q. Jin, J. Ji, The effect of ligand composition on the in vivo fate of multidentate poly(ethylene glycol) modified gold nanoparticles, Biomaterials, 34 (2013) 83708381.

[39] H.K. Makadia, S.J. Siegel, Poly Lactic-co-Glycolic Acid (PLGA) as Biodegradable Controlled Drug Delivery Carrier, Polymers, 3 (2011) 1377-1397.

[40] H.T. Chen, S.W. Kim, L. Li, S.Y. Wang, K. Park, J.X. Cheng, Release of hydrophobic molecules from polymer micelles into cell membranes revealed by Forster resonance energy transfer imaging, Proceedings of the National Academy of Sciences of the United States of America, 105 (2008) 65966601.

[41] N.J. Boylan, J.S. Suk, S.K. Lai, R. Jelinek, M.P. Boyle, M.J. Cooper, J. Hanes, Highly compacted DNA nanoparticles with low MW PEG coatings: In vitro, ex vivo and in vivo evaluation, Journal of Controlled Release, 157 (2012) 72-79.

[42] C. Banning, J. Votteler, D. Hoffmann, H. Koppensteiner, M. Warmer, R. Reimer, F. Kirchhoff, U. Schubert, J. Hauber, M. Schindler, A Flow Cytometry-Based FRET Assay to Identify and Analyse Protein-Protein Interactions in Living Cells, Plos One, 5 (2010).

[43] K.A. Foster, M. Yazdanian, K.L. Audus, Microparticulate uptake mechanisms of in-vitro cell culture models of the respiratory epithelium, Journal of Pharmacy and Pharmacology, 53 (2001) 5766.

[44] L. Li, H. Wang, J.X. Cheng, Quantitative coherent anti-Stokes Raman scattering imaging of lipid distribution in coexisting domains, Biophysical journal, 89 (2005) 3480-3490.

[45] B. Pelaz, P. del Pino, P. Maffre, R. Hartmann, M. Gallego, S. Rivera-Fernandez, J.M. de la Fuente, G.U. Nienhaus, W.J. Parak, Surface Functionalization of Nanoparticles with Polyethylene Glycol: Effects on Protein Adsorption and Cellular Uptake, ACS nano, 9 (2015) 6996-7008.

[46] S.Y. Lee, J.Y. Tyler, S. Kim, K. Park, J.X. Cheng, FRET Imaging Reveals Different Cellular Entry Routes of Self-Assembled and Disulfide Bonded Polymeric Micelles, Molecular Pharmaceutics, 10 (2013) 3497-3506. 
